\title{
R-EPOCH Regimen
}

National Cancer Institute

\section{Source}

National Cancer Institute. R-EPOCH Regimen. NCI Thesaurus. Code C63461.

A regimen consisting of rituximab, followed by a continuous infusion of etoposide,vincristine and doxorubicin, given with prednisone and a bolus dose of cyclophosphamide, used for the treatment of aggressive forms of non-Hodgkin lymphoma, including mantle cell lymphoma. 